\title{
Reframing market-orientation: A comparative study of the market orientation concept in the subcultures of university employees
}

\author{
NICK CHANDLER* (1), BALÁZS HEIDRICH, KARINA SZÁSZVÁRI and \\ RICHÁRD KÁSA
}

Management Department, Budapest Business School, Budapest, Hungary

Received: February 11, 2021 • Revised manuscript received: May 10, 2021 • Accepted: June 10, 2021

Published online: June 25, 2021

(C) 2021 The Author(s)

\begin{abstract}
In a higher education institution, perceptions and values are split due to the emergence of subcultures, and market orientation is split into competitive, customer (student) and interfunctional orientation. This study seeks to shed light on the concept of market orientation in this context through a comparison of perceptions and values of market orientation in subcultures in a higher education institution in Hungary and consider avenues for potential best practice. Through a mixed method approach, subcultures are identified and are found to exhibit a combination of overlapping and disparate market-oriented values and perceptions. Market orientation is found to be a continuum and affected by an array of latent variables, such as level of support (institutional and collegial), attitudes to performance appraisal and extent of external focus. Management must tailor the initial message of a market orientation strategy to the shared values at the organizational level, and then adjust the message and incentives to each subculture. In this way, management can create an atmosphere of cohesion, whilst addressing diversity in subcultures.
\end{abstract}

\section{KEYWORDS}

market orientation, subcultures, higher education, vignettes

JEL CLASSIFICATION CODES

M31, M14, I23

*Corresponding author. E-mail: chandler.nicholas@uni-bge.hu 


\section{INTRODUCTION}

Market-orientation (MO) in higher education (HE) is well established in many countries (Guilbault 2018) and has a large impact upon the performance of a higher education institution (HEI) (Zebal - Goodwin 2012). However, both practitioners and researchers have found the conceptual meaning of market orientation problematic in a HE context (Ottesen - Gronhaug 2002, 2004; Guilbault 2018; Ketchen et al. 2007; Marginson 2018; Akonkwa 2009).

Perceptions and values of employees regarding what constitutes a marketing orientation have been found to correspond to performance of employees in HEIs (Webster - Hammond 2018). However, the expectation of a single uniform perception of what is meant by market orientation in this context seems unlikely (Akonkwa 2009; Byrne et al. 2019), especially given the potential emergence of subcultures in large complex organisations such as HEIs (Gregory 1983). Despite this, heterogenous subcultures have the potential to deepen and develop our understanding of the concept of market orientation in the HE context (Tummons 2020).

Recent and on-going educational reforms in Hungary have highlighted the important role of a market orientation (Vasilache et al. 2012; Amsler 2008; Perryer - Egan 2015). There is an evident research gap in examining market orientation in HEIs (Vaikunthavasan et al. 2019). Ravishankar et al. (2011) found that research on subcultures is negligible and is focused on their effects on organizational performance and success (e.g. Lok - Crawford 1999: De Long 1997: Jung et al. 2016). Many studies also tend to opt for a monolithic culture perspective, even for large complex organizations (Lok et al. 2011). Moreover, Chatman and O'Reilly (2016) highlight important gaps in research in cultivating, managing and maintaining organizations with divergent subcultures.

The need for research into both subcultures and market orientation in higher education is highlighted by Akonkwa (2009), who contends that the usefulness of market orientation strategies in higher education are dependent upon research into both the market orientation concept and related issues for its application, such as the potential barrier of organisational culture (Raaij - Stoelhorst 2008).

In order to uncover the nature of subcultures in relation to a market orientation in the higher education context, the research question for this study is: what is understood as a market orientation by subcultures in higher education? In a nutshell, we seek to explore and compare values and perceptions of employee subcultures at a university with two aims: as a means towards bridging the evident gap in research on these two themes, as well as deepening our understanding of the concept of market orientation in universities. We also aim to put forward possible best practice to aid organisations involved in planning and/or implementing market orientation strategies in higher education in general, and in Hungarian higher education in particular.

In this paper, the conceptual framework for the study is presented, and then existing research concerning market orientation in higher education is examined, followed by empirical studies of the link between market orientation and culture (and subcultures), and a brief overview of the organizational context for this study.

\section{CONCEPTUAL FRAMEWORK}

This study is concerned with two elements: subcultures and market orientation. In this section the theoretical development and operational definitions that form the basis of this study are introduced. 


\subsection{The concept of subcultures}

Hofstede (1980: 25) describes culture as the "collective programming of the mind which distinguishes the members of one human group from another". This definition has been applied on a national, organisational and subcultural level to consider cultural differences. The operation definition employed in this study specifically refers to subcultures as “. . a subset of an organization's members who interact regularly with one another, identify themselves as a distinct group within the organization, share a set of problems commonly defined to be the problems of all, and routinely take action on the basis of collective understandings unique to the group" (Van Maanen - Barley 1985: 38; Schein 2004).

Although some studies identified organizational culture as either purely homogenous (a single unified culture) or entirely heterogeneous (only subcultures) (Martin 2002), Hatch (1997) highlighted that an organizational culture can be comprised of increasingly diversified subcultures, with, for example, both a large dominant culture (homogeneity) and a range of smaller subcultures (heterogeneity). Furthermore, variances in diversity of values from a larger dominant culture has been found to be due to similarities in pivotal (orthogonal subcultures), peripheral values (countercultures), or both (enhancing subcultures) (Boisnier - Chatman 2003). Hatch (1997) also theorized that organizational culture may take one of a number of different possible forms: unified (a single homogenous culture); integrated (a number of subcultures but all with the same values as the organization and some shared values between subcultures); slightly differentiated (with some subcultures having values at odds with the organization, but many in line with it, and some subcultures sharing a number of, but not all, values); significantly differentiated (with most but not all subcultures at odds with the organization's values and having no common values with other subcultures); and disorganized (where all subcultures appear at odds with the organization and one another, signifying a fragmented culture with isolated subcultures). This view of subcultures having a combination of values distinct with the dominant culture whilst others are intertwined to differing degrees has also been found in studies of societal subcultures (see Cheung - Liu 2015: 418).

\subsection{The concept of market orientation}

Narver and Slater (1990) identify two important areas for this study. First, their studies employ a concept of market orientation with a heavy focus on the organisational culture. Second, market orientation is split three ways: a customer, competitor, and interfunctional (cooperation) orientation. A customer orientation places priority on generating intelligence about customers' current and future needs. Likewise, a competitor orientation in an organization will, for example, push employees to discover and assess competitors' capabilities and strategies. In this way, a market orientation necessitates intelligence gathering and analysis, which in turn also requires intelligence sharing throughout the organization, as well as a need for coordinated action as a means of creating customer value that is superior to that of competitors (Narver Slater 1990). Thus, for these activities an interfunctional orientation is an important prerequisite.

In a higher education context, empirical evidence suggests market orientation is split into student, competitive and interfunctional orientation (Hemsley-Brown - Oplatka 2010). With a range of elements, it is not conceivable that organisations be considered as either market-oriented or not, but rather as a continuum whereby some elements are present and some are not, and to varying degrees or as referred to by Narver and Slater (1990), market orientation in this 
context is a 'sliding scale'. The problematic understanding of the concept of market orientation in higher education is emphasized by Marginson and Rhoades (2002: 287) as "universities have not been reduced to businesses. If the profit motive has been inscribed in these not-for-profit entities, higher education institutions nevertheless continue to be many-sided entities performing a wide variety of roles for various constituencies".

\section{MARKET-ORIENTED SUBCULTURES IN HIGHER EDUCATION}

Early works in market orientation have identified organisational culture as a critical barrier to a market orientation (Messikomer 1987), and this has continued as a topic of research with works such as Papadimitriou and Kargas (2012) who empirically tested and found a link between organizational culture and market orientation. Raaij and Stoelhorst (2008) highlighted how elements of culture drive the desired market-oriented behaviours, citing Homburg and Pflesser (2000) and Narver et al. (1998). Day (1999) also highlights the important link between culture and market orientation by recommending that any effort to develop market orientation requires an alignment with the organisation's culture. This issue of alignment is an important one in the HE context for two reasons. Firstly, as previously mentioned, there is a high potential for the emergence of subcultures in HEIs, which then raises the issue of whether all subcultures need to be aligned for ensuring market orientation success. Secondly, there is a potential divergence of values as Bok (2003) pointed out that the growing commercialization of HEIs undermines core academic values. Lynch (2006: 6) argues that a focus on a market (competitive) orientation and, more specifically, league tables "direct us away from many of the core values that are central to University work, including quality teaching, outreach, inclusion and research". This potential for divergence of values and perceptions when it comes to market orientation in this context, increases the likelihood of subculture formation (Kohli and Jaworski 1990). This phenomenon has been found in studies beyond the higher education sector, such as Carrington and Combe's (2013) study of market-oriented subcultures in the health sector, who found that subcultures were split into two: one focussing on the suppliers of the service and the other focused on the receivers of the service. Kasper (2005: 6) warns about viewing cultures as either market-oriented or not and suggests "a scale ranging from being truly market-oriented to not being market oriented at all".

Whether researching organizational culture or subcultures, one of the more common frameworks for assessing culture types is the Competing Values Framework (Quinn - Rohrbaugh 1983). It makes use of two bipolar axes as a means of indicating four orientations of culture (Cameron - Quinn 1999: 32). The 'Clan' culture is characterized by internal cohesiveness with shared values, participation and collectivism with a focus on internal problems and concerns of individuals. The 'Adhocracy' culture uses ad hoc approaches to solve problems incurred from the surrounding environment and indicates a willingness to take risks, creativity and innovation and independence and freedom are highly respected. The 'Hierarchy' has centralized decision-making, much formalized structures and rigidity with policies, instructions and procedures aimed at reducing uncertainty and enforcing stability. The 'Market' culture is based on an external focus on the market (market share) with a focus ambitious, quantifiable goals coupled with a competitive nature.

Applying our 'three-element concept of market orientation', it seems that each culture type has a potential link to aspects of this market orientation concept. The clan's focus on 
cohesiveness and collaboration seems to indicate a prevalence towards the interfunctional aspect of market orientation. For the adhocracy type, innovation certainly has a role to play in market orientation, although not listed in the literature as an element of market orientation in a higher education context and the external focus of this culture type may be linked to both the student and competitive aspects of market orientation. The focus of the hierarchy type on internal workings may be related to both student and interfunctional orientations as rules and procedures are established with the students' interests (and satisfaction) in mind, as well as to ensure interfunctional collaboration. The market culture type has an external focus, linked to a focus on students (customers) and competitors and a reliance on stability and control as a means of encouraging collaboration and intelligence sharing, i.e., interfunctional orientation.

Based upon these findings of the peculiarities of the HE context in general, the following section gives an overview of the organization that is the focus of the study.

\section{CONTEXT OF THE STUDY}

This study focusses on a sample from the Budapest Business School (BBS), also known as the University of Applied Sciences. Alongside the doctoral school, the university is comprised of three faculties: the Faculty of Commerce, Hospitality and Tourism (FCHT), the Faculty of International Management and Business (FIMB) and the Faculty of Finance and Accountancy (FFA). It is comprised of 396 teaching / research staff and 772 other staff (management, administrative support, etc.). It has 11 undergraduate courses and 3 Master's courses, with some of these courses also held in foreign languages.

Of particular relevance to this study, the university places value on its market recognition due to the experience-based, practice-oriented programme structure which is continuously adapted to market needs. In terms of market position, BBS is the number one business training university in Hungary, with nearly 17,000 students in Business-related topics, including Tourism and Catering, International Economy and Business, Commerce and Marketing, Finance and Accountancy, Business Administration and Management and Business Information Technology and Human Resources. According to data from March 2021, it is the number one choice for those interested in business training, and in 2021 became the third most popular university in the country after ELTE and the University of Debrecen. The University has many courses that are classed in the top 10 of undergraduate courses in the country: trade and marketing, farming and management, tourism and hospitality, finance and accounting, and international management.

From a competitive perspective, Hungarian Universities have the difficulty of competing whilst coping with scarce government funding and declining foreign direct investment (Lentner 2007). According to the OECD (2017), there is significant competition in certain disciplines within the higher education system in Hungary, which impedes collaboration and the creation of HEI clusters in specific disciplines, along with their associated benefits. From an international perspective, 13 Hungarian higher education institutions have increased their existing rankings in recent years and more and more Hungarian Universities appear in the rankings. However, the majority of these Hungarian universities appear in the middle or last third of the rankings, with a few exceptions.

This a crucial time for assessing the market orientation of a Hungarian University. Along with the majority of large universities in Hungary, the university decided in early 2021 to opt for 
undergoing a change of operational model with the aim of increasing the flexibility and competitiveness of higher education. The new form of operation will not only be closer to the current market-based operation and spirit of the university but is also intended to create a more advantageous and distinguished position for the development of talent and performance of students, faculty and colleagues. Thus, a study of market orientation at a Hungarian University has a lot to offer for both researchers and practitioners concerned with the effects and outcomes of the model that is soon to be implemented.

\section{METHODS AND MATERIALS}

\subsection{Study design and setting}

A single organisation was chosen for this study since cultural theory dictates that the culture of each organization is specific (Hatch 1993; Schein 1995) and some studies have opted for indepth studies in a single university when expounding the concept of market orientation (e.g., Küster - Avilés-Valenzuela 2010). Whilst this may present problems with the generalizability of the findings, the focus of this study is to explore the phenomenon of market orientation in higher education through the lens of subcultures as a means of deepening understanding of the concept, as well as potentially providing indications of best practice, and the role of the subcultures in the market orientation of a university.

A mixed-method study was undertaken to uncover as much as possible about subcultures and market orientation (Bryman 1988; 2006). Although using different instruments, Sarkar et al. (2020) also used a mixed-method approach to explore the effect of subcultures in a healthcare setting. The first phase involves the identification of subcultures, based upon expressed values. The second phase involves exploring the key elements of market orientation based on perceptions and values in each subculture. Cresswell (2003: 211) highlights the need to consider the implementation sequence of data collection, to decide which method takes priority. For the first phase, a quantitative method is used to identify subcultures. In the second phase, focus groups were set up with the aim of forming discussions based on four vignettes. Based upon Cresswell (2003), our approach can be considered as sequential and explorative as both phases are aimed to explore a concept, i.e., market orientation, and, by necessity, the one must precede the other.

\subsection{Procedures}

Approval, consent, and input to the design of the study were obtained from a representative of the university's governing body prior to distribution of the questionnaires. A summary of the project was prepared in Hungarian for participants.

The two-phase approach presented a particular challenge with regard to anonymity (Kvale 2007). The questionnaire required anonymity to be assured, however, for the second phase the participants willing to take part in focus groups needed to be identified. To overcome this, respondent contact details were required only if they agreed to take part in focus groups in phase two. The email address that constituted the contact details was separated from the dataset in phase one before the responses were analysed to keep the data anonymous. After the initial analysis, the filter was re-applied to select participants from the subcultures via the email address provided by them. Those participating in focus groups were assured at the beginning of focus 
group discussions that identifying data had been purged from all records, all recordings of focus groups would be destroyed after analysis, no-one else beyond the research team would have access to the data and that no future publications and reports would have identifying data in them, as well as an invitation to see and comment on draft versions (Parker - Tritter 2006). No part of the study was undertaken without consent of all participants.

\subsection{Choice of sample}

The target population is the employees of the institution. Multi-stage sampling is employed in this study as the study moves from a broad to a narrow sample (Ackoff 1953). In the first phase, purposive sampling was employed as used by Akhtar and Arif (2011) in a similar context and with the same cultural assessment instrument. The sample (267) contained $71(27 \%)$ male employees and 196 (63\%) female employees. The age structure is as follows: $84(31.5 \%)$ under the age of 30 years; 108 (40.5\%) are between 31 and 45 years old; 75 (28\%) are above 45 years. In terms of function: 107 (40\%) administrative staff, 120 (45\%) teaching and research, and 40 (15\%) management. Only full-time employees who had been with the organization for at least a year were selected for the sample.

For the second phase, cluster sampling was employed based upon subcultural groupings from the first phase and a purposive sample was taken from these clusters, for use in the final sample to reflect a range of ages, occupation, and gender (Wilson 2010) as much as possible in the focus groups for each subculture. Thus, from 41 willing participants, 16 were selected.

\subsection{First phase: quantitative}

The organizational culture assessment instrument (OCAI) has been selected for identifying subcultures in this study. It was originally developed for an educational context by Quinn and Rohrbaugh (1983). Although the OCAI has already been used in Hungary as a means of assessing culture types in Hungarian enterprises (Gaál et al. 2010), the three-step process for rigorous translation procedures of Su and Parham (2002) was employed to develop the Hungarian version of the OCAI.

A quantitative method previously used by Hofstede (1998) is used for the task of identifying subcultures, based upon employee values, and uses Hierarchical cluster analysis (Ward's method). The number of splits is detected using a process resembling "scree analysis".

\subsection{Second phase: qualitative}

Vignettes have been suggested for contrasting differing perceptions and attitudes (Barter Renold 1999; Hughes 1998) and ensuring all members of the focus group voice an opinion, which is crucial for uncovering what is valued and perceived by subcultures regarding a market orientation. Vignettes are described as short scenarios in written or pictorial form, intended to elicit responses to typical scenarios (Hill 1997: 177). They involve concrete examples of people and their behaviours and serve as the means for participants to offer comment or opinion (Hazel 1995: 2). Working in focus groups results in a closer approximation to natural interaction in the subcultures than other data collection strategies (Kamberelis - Dimitriadis 2013: 46).

The use of vignettes as a complementary technique alongside other data collection methods can help to explore data that cannot be uncovered through, for example, interviews or observation (MacAuley 1996) and deal with sensitive topics (Blum et al. 2019). The vignettes were 
developed based upon our findings in the literature that in a higher education context, market orientation is based upon student, competitive and interfunctional orientation. It was found during the pilot study that interfunctional orientation was a provocative issue and raised overtly sensitive topics between employees in different departments. Therefore, this element of market orientation was omitted from vignettes and the vignettes were designed to uncover student and competitive orientations as well as the core values and perception of each subculture, as displayed in Table 1.

Table 1. MO focus, intent and wording of vignettes

\begin{tabular}{|c|c|c|c|}
\hline No. & MO Focus & Intent & Wording \\
\hline 1 & Student as a customer & $\begin{array}{l}\text { Studies have found students having } \\
\text { to pay fees is linked to view of the } \\
\text { student as a customer by both staff } \\
\text { and students (e.g., Delucchi - } \\
\text { Korgen 2002) }\end{array}$ & $\begin{array}{l}\text { A group of students has been } \\
\text { asked to submit an assignment in } \\
\text { three days. On the day of the } \\
\text { deadline one of the students } \\
\text { approaches the teacher and asks } \\
\text { for an extension. The student } \\
\text { doesn't give a reason but says that } \\
\text { after paying course fees they } \\
\text { should be entitled to some } \\
\text { leniency. What will happen next? }\end{array}$ \\
\hline 2 & $\begin{array}{l}\text { Extent of student } \\
\text { orientation }\end{array}$ & $\begin{array}{l}\text { This vignette raises the issue of the } \\
\text { flexibility of the staff (Nunan 1999) } \\
\text { and degree of concern for helping } \\
\text { the student (Elliot 2002) }\end{array}$ & $\begin{array}{l}\text { András is a student who is } \\
\text { struggling with the basics of the } \\
\text { course materials, and it is clear by } \\
\text { the fourth week that he has little } \\
\text { chance of passing. The student } \\
\text { says his parents are not well off } \\
\text { and paid for the course with their } \\
\text { savings. What will happen next? }\end{array}$ \\
\hline 3 & Competitive orientation & $\begin{array}{l}\text { Staff are faced with a choice with } \\
\text { two areas of market orientation: a } \\
\text { shared IT system (interfunctional } \\
\text { /collaboration: Kohli - Jaworski } \\
\text { 1990) or views on competition. }\end{array}$ & $\begin{array}{l}\text { A university is struggling to get } \\
\text { enough students. Another university } \\
\text { is completely focussed on poaching } \\
\text { their students through any means } \\
\text { necessary. At the same time, an IT } \\
\text { system was recently introduced for } \\
\text { all staff, but this has led to conflict } \\
\text { and demotivation. The university } \\
\text { needs a strategy of what to focus } \\
\text { on. What should it be? }\end{array}$ \\
\hline 4 & $\begin{array}{l}\text { Core values of the } \\
\text { subculture }\end{array}$ & $\begin{array}{l}\text { Open question to raise issues held } \\
\text { as important or key concerns within } \\
\text { each subculture. }\end{array}$ & $\begin{array}{l}\text { The Ministry of Education is } \\
\text { drawing up a list of the main issues } \\
\text { to be considered in the future of } \\
\text { higher education. Which issues } \\
\text { should be on that list? }\end{array}$ \\
\hline
\end{tabular}

Source: authors. 


\subsection{Interpretation}

For the data analysis process, a realistic approach was taken (Silverman 2015), assuming that employees drew potentially valid pictures of market orientation, albeit from different perspectives, i.e., the researcher is 'mining' through the use of vignettes for objective real data or subjective authentic meanings (Kvale 2007). Comparisons of perspectives and values across heterogeneous subculture groups are used to build an understanding of market orientation in the HE context (Tummons 2020).

The authors took on the role of insider researchers (Trowler 2012). This type of research requires treading a fine line between remaining sufficiently close and yet still keeping a certain degree of distance, to ensure a valid analysis. As the research team comprised management, administrative staff and teachers, this endogenous study made use of emic accounts that emerged during discussions in focus groups (Trowler 2012). The issue of power relations corrupting the results (Mercer 2007) were overcome as the study was managed and represented by a non-Hungarian as an outsider and with no implications of holding a powerful position, which might have affected the willingness of participants to have a frank and open discussion about the vignettes (Trowler 2012).

The transcripts from focus group discussions were used to perform a content analysis. A double coding protocol was followed, i.e., each focus group discussion was coded by at least two persons from the research group, as a means of reinforcing the validity of the coding process. The first phase of coding was followed by research group discussions (Mcpherson - Nunes 2006), whereby the entire research team worked towards a common understanding of the results i.e., what elements could be considered as values or perceptions relating to a market orientation. As a result of these discussions, the coding process was refined, wherever deemed necessary (Saldaña 2013).

Following the refinements in the coding, a further research focus group discussion was held to reach a common interpretation of the meaning of the coded material and to identify patterns in the values and perceptions. These two research group discussions served to increase the intersubjective or communicative validity (Kvale 1995) of the analysis phase.

\section{RESULTS}

\subsection{First phase}

For the first phase of our study, we assessed the reliability of our sample of 267 participants, as shown in Table 2.

Based upon the values (involving 24 values in total per participant), five clusters were found, and their dominant culture type can be seen in Table 3. Three members were considered outliers, hence the total number of members in the clusters is 264 .

As there are three clusters with the same culture type, an ANOVA analysis was undertaken to determine if there is a significant difference across the clusters, presented in Table 4.

As can be seen in Table 4, significant differences were found across the three clusters with the same culture type.

\subsection{Second phase}

There were 5 participants for a market type focus group (cluster 5), 6 for a 'standard clan' (cluster 2), and 5 for a strong clan (cluster 4). Due to a lack of availability and low number of 
Table 2. OCAI reliability statistics using Cronbach's alpha

\begin{tabular}{|l|c|c|}
\hline Culture type & Cronbach's Alpha $\alpha$ & Comparison Reliability Coefficients* $^{*}$ \\
\hline Clan & 0.810 & 0.82 \\
\hline Adhocracy & 0.785 & 0.83 \\
\hline Market & 0.778 & 0.77 \\
\hline Hierarchy & 0.871 & 0.78 \\
\hline
\end{tabular}

* Reliability coefficients reported by Cameron and Quinn (1999).

Source: authors

Table 3. Hierarchical cluster analysis by culture type and number of members

\begin{tabular}{|l|c|c|c|c|c|}
\hline & Cluster 1 & Cluster 2 & Cluster 3 & Cluster 4 & Cluster 5 \\
\hline Culture type & Hierarchy & Clan & Extreme Clan & Strong Clan & Market \\
\hline No. of members & 96 & 78 & 9 & 57 & 24 \\
\hline
\end{tabular}

Source: authors

Table 4. ANOVA analysis of clusters based on means relating to clan values

\begin{tabular}{|l|c|c|c|c|c|}
\hline & Sum of Squares & df & Mean Square & F & Sig. \\
\hline Between Groups & 88.36 & 36 & 2.45 & 5.76 & 0.000 \\
\hline Within Groups & 21.72 & 51 & 0.43 & & \\
\hline Total & 110.08 & 87 & & & \\
\hline
\end{tabular}

Source: authors.

willing participants from the hierarchy and 'extreme clan' subcultures for the focus groups, they have been omitted from the second phase of the study. This finding in itself begs the question of whether the unwillingness of the hierarchy subculture members to participate is a characteristic of this culture type and, if so, how this may impact upon aspects of market orientation such as information sharing and collaboration. Whilst the subcultures could have offered further insight into the concept of market orientation, this finding still offers an avenue for further research and doesn't negate from the insight the other subcultures can offer towards the concept of market orientation in a higher education context.

For clarity, the common and differentiating perceptions and values have been grouped together into two Venn diagrams based upon the findings from all four vignettes.

In Figure a, all three subcultures expressed a degree of uncertainty in the workplace and, alongside this, the need for rules. Stability and control are not characteristic of the clan subculture type according to the OCAI, but the common desire for rules across all subcultures may 
indicate a desire for rules to overcome the sense of uncertainty as seen on a national level with Hungary's high uncertainty avoidance being linked to a need for rules and rigid codes of behaviour (Falkné Banó 2014). The need for welfare links to a need for security and safety as employees expressed a need to be 'looked after', as employees. The topic of concern also arose for the student in the two clan subcultures. The market culture, however, was less concerned for the student, but did see a need for combining a balance of flexibility, whilst upholding the rules for all. This delicate balance may be seen as a form of 'cognitive dissonance' or attempting a delicate balance between the two. Moreover, the market culture tended to focus on the bigger picture of the market as a whole. Values were placed on being led and being 'made to be committed' of the market subculture, which may be indicative of an external locus of control, as well as a preoccupation with external factors. In contrast, the clan cultures took a view of how to deal with students, with a professed need for a positive approach, seeing the best in students (strong clan) and a move away from systematic and out-dated approaches to dealing with students (clan). Both clans considered the human side: how students should be dealt with fairly (strong clan) and focus on their welfare (clan). However, there was also underlying this, a value placed support for staff in the clan culture, which could also stem from this atmosphere of uncertainty.

Whilst there remains the underlying uncertainty and need for rules, there is a deep contrast in value and perceptions for competitive orientation compared to student orientation, despite both constituting elements of a market orientation. The clan cultures saw competition as not having a place in higher education (clan) or simply not considered due to a strong internal focus (strong clan), which was termed in the focus group as 'navel-gazing'. The only external focus that arose was in relation to the role of higher education in society (strong clan), and both clan subcultures referred to the importance of the reputation in terms of credibility both of educators and the institution as a whole. Alongside the internal focus, both clans expressed a need for a mentor approach to colleagues as a form of support and development. This collaborative aspect was also expressed in the strong clan in the form of the need for cross-functional teams to improve quality via a mix of employees from the areas of administration, research and teaching.

For both the student and competitive orientation, the market subculture expressed concurrent values on the need for rules and for flexibility. Although these are opposing dimensions of the framework used in Phase One of the study, the Competing Values Framework allows for cultures or subcultures to have a mix of culture types through the use of an ipsative scale. A strong market culture might have a high value on the stability and control dimension and a correspondingly low value for flexibility and discretion. Whereas a less strong, (but still dominant) market culture may have lower values for stability and control, and higher values for flexibility and discretion, but not high enough to shift the typology from a market to an adhocracy subculture. In this way, it is feasible within the model for a market culture type to have slightly values relating to stability and control, as well as values pertaining to flexibility and discretion, albeit to a lesser extent.

Compared to clan cultures, the market culture exhibited a heightened focus on reputation and referred to the employer brand, alongside the need for rules. Although performance evaluation in relation to a competitive orientation is concerned with benign competition between employees, it has been added here to the Venn Diagram as it was discussed as a method of achieving higher quality standards in the face of competition in the market subculture. In contrast, the clan subculture also raised the issue of performance appraisals but rather with an 
internal focus on how performance appraisals will clarify to employees the requirements and standards by which staff are expected to work.

\section{DISCUSSION}

The literature indicated that there are elements of integration and differentiation between subcultures, and this phenomenon has been found in both phases of this study. The quantitative study found subcultures of the same type (clan culture) but significant differences on the basis of strength of these values, according to the figures assigned to them. The qualitative study also found differences and similarities between subcultures in perceptions of market orientation. For example, in the socialization of colleagues and the mentoring of students, the clan and market culture types seem to converge, although this convergence derives from a different perspective. From clan (or strong clan) this is more an emotional attitude to the customer (student), whereas for the market subculture this attitude derives purely from organisational efficiency issues. This corroborates the theoretical quantitative model, as the market culture type values stability and control and the clan subcultures' preference for the human connection involving a more 'emotional attitude' to other people in the organization.

The themes of the vignettes were split, based upon the literature, into student orientation and competition orientation. For the first of these, our findings indicate student orientation varies across subcultures, leading to different roles. The two clan subcultures combined a supportive and collaborative approach with a concern for the customer: "I reminded him about the overdue deadline and offered my help" (Vignette 1) and "part of the service is to train them the correct behaviour". The clan subcultures seemed accommodating to students: "part time students often study next to work and family". Whilst both clan subcultures exhibited a paternalistic approach with a desire for rules an support for students, combined with a concern for the student, the clan focus group repeated this aspect more frequently, such as with "the need for clear requirements and guarantees" and "being late has its consequences", whilst still exhibiting a concern for the welfare of students. In contrast, the market subculture showed less flexibility to the student (customer) and a focus on rules and the consequences of breaking them: "there are no exceptions"; "students have to take responsibility for their decisions"; and "the consequences (of being late) mirror the consequences of being late for the whole system" (Vignette 1). This finding also confirms the literature that there is a sliding scale in relation to the market orientation concept but builds on the literature though the subcultural perspective. The strong clan indicated flexibility and discretion toward the customer, the clan was less flexible and more controlling, whereas the market subculture was rigid and sought stability and control. This also reflects the theoretical basis of the quantitative instrument, where market culture types are oriented towards stability and control and clan cultures toward flexibility and discretion.

For competitive orientation, the findings also confirm that market orientation is a sliding scale rather than 'one or the other'. The topic of performance appraisal arose and was discussed in all three focus groups. It was also found in the literature to be a part of the competitive orientation. A sliding scale was found across subcultures in the openness of the culture to external factors affecting performance appraisal. It came across that the strong clan subculture is closed, with an internal focus on teams and the need for bottom-up initiatives. For the slight clan, the subculture considered all elements, both external and internal, causing the dilemma: 
"who is responsible for underperformance? The teacher, the student or the organization?" Conversely, for the second vignette, the market culture was firmly and resolutely focused on the customer, as well as external benchmarks: "Everyone should do everything for the sake of the quality of the service and transparency requirements - professionalism comes first".

Vignette 3 focused on perceptions of competition and demonstrated distinct differences. The strong clan focus group overlooked the customer or competitive aspects: and focused on the role of HEIs in providing a service beneficial to society. When faced with the threat of competition, the slight clan focused on a need for nurturing and collaborating: "There is no tutoring or mentoring between instructors, no support for education, and no knowledge sharing. I give just expectations without a supporting system" and indicated that the market had no role to play in higher education. This also highlights the need for interfunctional cooperation, which was extracted from this study, but is clearly linked to the other two market-orientation elements from the comments raised. Furthermore, support was seen in the subculture as made up of two aspects: institutional support and collegial support. These two aspects were raised in relation to both student and competition orientation. The market culture group (vignette 3 ) focused on traditional marketing elements such as brand reputation and quality perspective coupled with the need for someone to take control of ensuring quality: "Who tells the usefulness of assignments, who tells me what my communication skills are like, whether they are good or not?"

These findings point to a number of suggestions for best practice that may aid universities that are wrestling with the planning and implementation of a market orientation. Best practice would be for HEIs to undertake a diagnostic approach to organizational cultures in higher education, as recommended in other studies such as Raaij and Stoelhorst (2008). Building upon this, our findings indicate the need for an additional step of identifying the values that diverge and converge across subcultures. The identification of subcultures will aid in the communication of a desired market orientation, as the management can use the common and diverse values as a means of tailoring the message concerning the introduction or reinforcement of a market orientation at a university to specific subcultures. After management has developed a list of desired values and behaviours relating to a market orientation (see Raaij - Stoelhorst 2008: 1285), then management can compare current values to those desired.

Through this diagnostic approach, management can consider if commonly held values across all subcultures present obstacles to a market orientation, or if a certain specific set of values belonging to one or a handful of subcultures need attention (as shown in Figs 1 and 2 in this paper). Thus, this approach will uncover whether organisation-wide alignment is required or a focus on specific subcultures, thereby potentially improving the effectiveness of change programmes relating to market orientation. For practitioners, this may involve practices such as the reinforcement of a common goal or the introduction of a system of subculture-oriented incentives to encourage market-oriented behaviours, similar to the practice of team-based incentives.

Subcultures perceived a lack of support within the HEI when it came to handling the customer and competition, which implies either insufficient communication of policies supporting the employee, or a need for the development and introduction of policies regarding the customer and how to achieve success in the face of competition.

Handling the customer varied across subcultures from the rigid to flexible and accommodating. Furthermore, in the face of competition, some subcultures buried their heads in the sand whilst others looked for pragmatic aspects to 'beat the competition'. Market-oriented subcultures may serve as mentors or group leaders for those subcultures less externally focused and conversely 


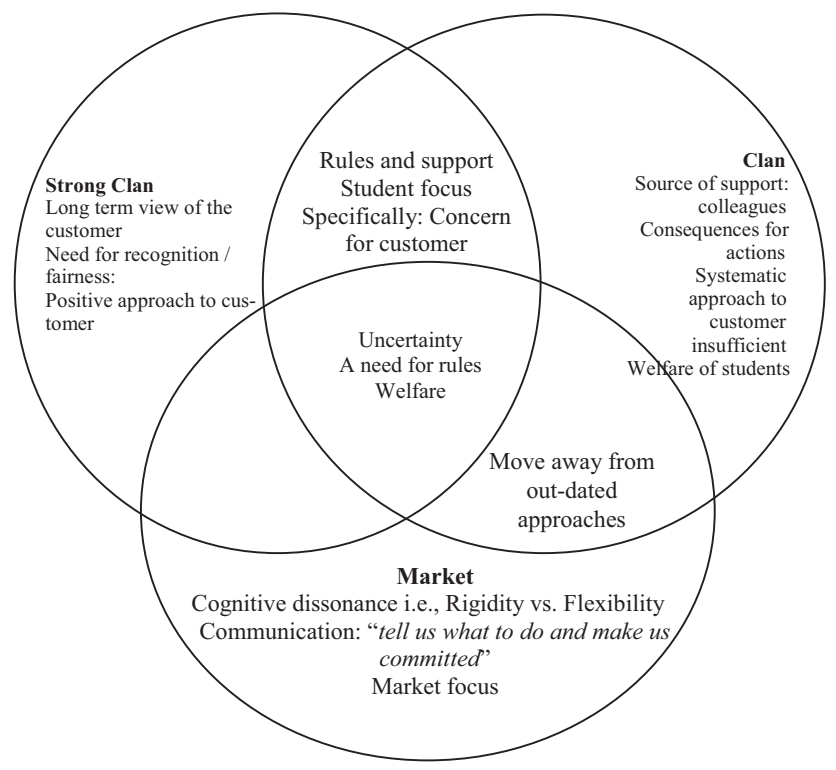

Source: authors.

Fig. 1. The values and perceptions of market orientation of the three subcultures relating to student orientation.

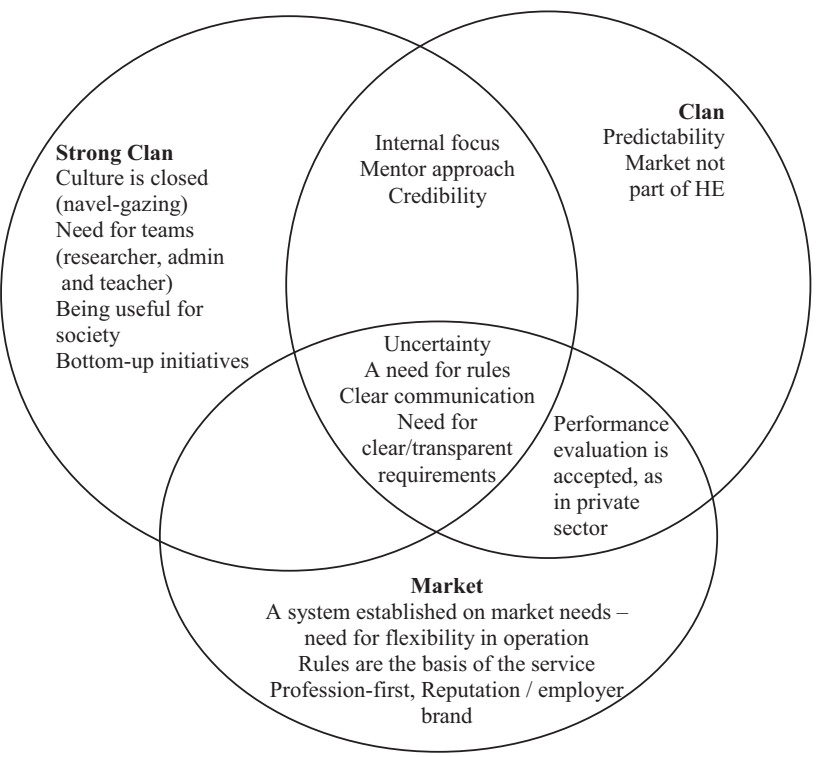

Source: authors

Fig. 2. The values and perceptions of market orientation of the three subcultures relating to competitive orientation. 
clan subcultures can mentor members of market-oriented subcultures in areas such as flexibility towards students, if management are looking for alignment across all subcultures (uniculturalism).

\section{CONCLUSIONS AND FUTURE RESEARCH DIRECTIONS}

The research question of this study was: what is understood as a market orientation by subcultures in higher education? With a mixed method approach it was found that the concept of market orientation (MO) in higher education does contain elements that indicate a sliding scale in relation to both the customer and competition orientations, confirming findings in the literature that an organisation's market orientation should not be considered as 'either marketoriented or not'. In this case, for large complex organizations, a generic understanding of market orientation is problematic from a cultural perspective, as it overlooks the relevant complexities and nuances regarding employee values and perceptions.

This study highlights the 'haziness' of the market orientation concept in an HE setting, not only with a sliding scale from a subcultural perspective but also the latent elements uncovered in this study relating to market orientation, such as level of support (institutional and collegial), uncertainty and ways to overcome it, and how an internal or external focus affects perceptions of, for example, the use of performance appraisal. It certainly provides avenues for further research into not only the market orientation in Hungarian HEIs, but extent of the effect of these latent variables.

From a subcultural perspective, the finding that organizational subcultures can be significantly differentiated based upon strength of values (see Table 4), is somewhat reminiscent of how extremist groups such as in politics or religion break off from the mainstream and form separate and distinct subcultures, despite being based on common core values. This finding highlights the need for further study into how subcultures interact with one another, such as whether they form alliances and collaborate in the face of other diverse subcultures or distance themselves based upon strength of values, as seen in distinguishing between a fanatical extremist and a moderate despite essentially having the same values.

The mixed method approach using vignettes in focus groups was successful in allowing subcultures to interact with other members and as a technique it brought to the surface deeper sentiments which were especially useful in examining the values and perceptions of subcultures. It seems a suitable method for getting insight into how the subcultures interact.

One limitation of this study is the omission of adhocracy and hierarchy subcultures in focus groups. Whilst rich data was still uncovered from the focus groups, these are strong potential research directions as they will have more to add to the concept of market orientation. However, the aim of uncovering more about the concept of MO in HE has been achieved through the three subcultures studied.

In this study, the cooperation orientation was omitted to avoid the potential for conflict between administrative, management and teaching staff, as found in the pilot study. However, some aspects of interfunctional orientation still arose in the form of collegial mentorship and support for colleagues. However, no mention was made in any of the focus groups of the functional differences between administration, teaching and management. This finding has not weakened the study but provided a rich source for further research as the pilot study uncovered a degree of 'duality' in that employees seemed to have unease in discussing interfunctional issues within subcultures, which in turn may have a huge impact upon the interfunctional element of a market orientation, and thereby market orientation itself. 
A large number of Hungarian universities are going through or about the to go through a change of operational model. For practitioners, the findings of this study present significant challenges for consideration prior to implementation of the new model and for researchers, present research directions for those in the fields of market orientation and organizational cultures in higher education. Moreover, the introduction of a new operational model could have detrimental effects on the already-existing uncertainty raised by all three subcultures. Practitioners will need to consider ways to reduce this uncertainty before, during and after the implementation of the model, possibly using some of the techniques suggested by focus groups in this study, such as the support from colleagues through mentoring, clarity of communication and clear rules and procedures for the new operational system, which could lead to a smoother transition as many Hungarian university cope with this transformation.

\section{REFERENCES}

Ackoff, R. (1953): The Design of Social Research. Chicago, IL: University of Chicago Press.

Akhtar, C. - Arif, A. (2011): Impact of Organizational Learning on Organizational Performance. International Journal of Academic Research 3: 327-331.

Akonkwa, D. (2009): Is Market Orientation a Relevant Strategy for Higher Education Institutions? Context Analysis and Research Agenda. International Journal of Quality and Service Sciences 1(3): 311-333.

Amsler, S. (2008): Higher Education Reform in Post-Soviet Kyrgyzstan. Structure and Agency in the Neoliberal University. In: Canaan, J. E. - Shumar, W. (eds): Structure and Agency in the Neoliberal University. London: Routledge, pp. 101-128.

Barter, C. - Renold, E. (1999): The Use of Vignettes in Qualitative Research. Social Research Update 25(9): $1-6$.

Blum, R.W. - Sheehy, G. - Li, M. - Basu, S. - El Gibaly, O. - Kayembe, P. - Xiayun, Z. Ortiz, J. - Chan, K. - Moreau, C. (2019): Measuring Young Adolescent Perceptions of Relationships: A Vignette-Based Approach to Exploring Gender Equality. PLoS One 14(6): e0218863.

Boisnier, A. - Chatman, J. (2003): The Role of Subcultures in Agile Organizations. In: Peterson, R. Mannix, E. (eds): LEA's Organization and Management Series. Leading and Managing People in the Dynamic Organization. Lawrence Erlbaum Associates Publishers, pp. 87-112.

Bok, D. (2003): Universities in the Marketplace: The Commercialization of Higher Education. Princeton: Princeton University Press.

Bryman, A. (1988): Quantity \& Quality in Social Research. London: Routledge.

Bryman, A. (2006): Integrating Quantitative and Qualitative Research: How Is It Done? Qualitative Research 6: 97-113.

Byrne, J. - Dwyer, T. - Doyle, D. (2019): Understanding the Layers of a Market-Oriented Organisational Culture. The Irish Journal of Management 37(1): 16-30.

Cameron, K. - Quinn, R. (1999): Diagnosing and Changing Organizational Culture. Reading, MA: Addison-Wesley.

Carrington, D. - Combe, I. (2013): Market Oriented Cognitive Subcultures in a Multiple Stakeholder Environment. In: Clegg, B. - Scully, J. - Bryson, J. (Eds): ESRC Research Capacity Building Clusters: Summit Conference 2013: 25th - 26th June 2013, Aston University. Birmingham, UK: Aston University, pp. 151-169. 
Chatman, J. A. - O’Reilly, C. A. (2016): Paradigm Lost: Reinvigorating the Study of Organizational Culture, Research in Organizational Behaviour 36: 199-224.

Cheung, C. - Liu, L. (2015): Revisiting the Subculture: Understanding Deviant Students in China. Asian Education and Development Studies 4(4): 409-422.

Cresswell, J. W. (2003): Research Design: Qualitative, Quantitative, and Mixed Methods Approaches. Thousand Oaks, CA: Sage.

Day, G. S. (1999): Creating a Market-Driven Organization, Sloan Management Review 41: 11-22.

De Long, D. (1997): Building the Knowledge-Based Organization: How Culture Drives Knowledge Behaviors. Ernst \& Young LLPCenter for Business Innovation Working Paper.

Delucchi, M. - Korgen, K. (2002): We're the Customer - We Pay the Tuition: Student Consumerism Among Undergraduate Sociology Majors. Teaching Sociology 30(1): 100-107.

Elliott, K. (2002): Key Determinants of Student Satisfaction. Journal of College Student Retention: Research, Theory \& Practice 4(3): 271-279.

Falkné Bánó, K. (2014): Identifying Hungarian Cultural Characteristics in Europe's Cultural Diversity in the 21st Century: A Controversial Issue. http://publikaciotar.repozitorium.uni-bge.hu/209/1/12\%20Falkn\% C3\%A9.pdf, accessed 09/04/2021.

Gaál, Z. - Obermayer-Kovács, N. - Csepregi, A. - Antonova, A. - Jenei, E. (2010): Clan, Adhocracy, Market, Hierarchy? Investigating Organizational Culture Types and Knowledge Sharing in Bulgaria, Hungary and Serbia. 5th International Knowledge Management in Organizations Conference at Veszprém, May 2010.

Gregory, K. L. (1983): Native-View Paradigms: Multiple Cultures and Culture Conflicts in Organizations. Organizational Culture 28(3): 359-376.

Guilbault, M. (2018): Students as Customers in Higher Education: The (Controversial) Debate Needs to End. Journal of Retailing and Consumer Services 40: 295-298.

Hatch, M. (1993): The Dynamics of Organizational Culture. The Academy of Management Review 18(4): 657-693.

Hatch, M. (1997): Organization Theory. Modern, Symbolic, and Postmodern Perspectives. New York: Oxford University Press.

Hazel, N. (1995): Elicitation Techniques with Young People. Social Research Update 12(4): 1-8.

Hemsley-Brown, J. - Oplatka, I. (2010): Market Orientation in Universities: A Comparative Study of Two National Higher Education Systems. International Journal of Educational Management 24(3): 204-220.

Hill, M. (1997): Research Review: Participatory Research with Children. Child and Family Social Work 2: 171-183.

Hofstede, G. (1980): Culture and Organizations. International Studies of Management \& Organization 10(4): 15-41.

Hofstede, G. (1998): Identifying Organizational Subcultures: An Empirical Approach. Journal of Management Studies 35: 1-12.

Homburg, C. - Pflesser, C. (2000): A Multiple Layer Model of Market-Oriented Organizational Culture: Measurement Issues and Performance Outcomes. Journal of Marketing Research 37: 449-462.

Hughes, R. (1998): Considering the Vignette Technique and Its Application to a Study of Drug Injecting and HIV Risk and Safer Behaviour. Sociology of Health and Illness 20(3): 381-400.

Jung, J. - Nam, C. - Lee, E. - Kim, S. (2016): Subculture by Autonomy and Group Cohesion and Its Effect on Job Satisfaction of R\&D Professionals in an R\&D Organization. Journal of Management \& Organization 22(2): 154-172. 
Kamberelis, G. - Dimitriadis, G. (2013): Focus Groups: From Structured Interviews to Collective Conversations. New York: Routledge.

Kasper, J. (2005): The Culture of Market-Oriented Organisations. METEOR, Maastricht Research School of Economics of TEchnology and Organizations No. 052.

Ketchen , Jr, D. - Hult, G. - Slater, S. (2007): Toward Greater Understanding of Market Orientation and The Resource-Based View. Strategic Management Journal 28(9): 961-964.

Kohli, A. - Jaworski, B. (1990): Market Orientation: The Construct, Research Propositions, and Managerial Implications. Journal of Marketing 54: 1-18.

Küster, I. - Avilés-Valenzuela, M. (2010): Market Orientation in University: A Case Study. International Journal of Educational Management 24(7): 597-614.

Kvale, S. (1995): The Social Construction of Validity. Qualitative Inquiry 1(1): 19-40.

Kvale, S. (2007): Doing Interviews. Thousand Oaks, CA: Sage Publications Inc.

Lentner, C. (2007): The Competitiveness of Hungarian University-Based Knowledge Centres in European Economic and Higher Education Area. Transformations in Business and Economics 6(2): 87-99.

Lok, P. - Crawford, J. (1999): The Relationship between Commitment and Organizational Culture, Subculture, Leadership Style and Job Satisfaction in Organizational Change and Development. Leadership \& Organization Development Journal 20(7): 365-374.

Lok, P. - Rhodes, J. - Westwood, B. (2011): The Mediating Role of Organizational Subcultures in Health Care Organizations. Journal of Health Organization and Management 25(5): 506-525.

Lynch, K. (2006): Neo-liberalism and Marketisation: The Implications for Higher Education. European Educational Research Journal 5(1): 1-17.

Maanen, J. - Barley, S.R. (1985): Cultural Organization: Fragments of a Theory. In: Frost, P. J. - Moore, L. Louis, M. - Lundberg, C. - Martin, J. (eds): Organizational Culture. Beverly Hills: Sage, pp. 31-53.

MacAuley, C. (1996): Children in Long Term Foster Care: Emotional and Social Development. Hampshire: Avebury.

Marginson, S. (2018): Global Trends in Higher Education Financing: The United Kingdom, International Journal of Educational Development 58: 28-36.

Marginson S. - Rhoades, G. (2002): Beyond National States, Markets and Systems of Higher Education: A Glonacal Agency Heuristic. Higher Education 43: 281-309.

Martin, J. (2002): Organizational Culture: Mapping the Terrain. Thousand Oaks, CA: Sage Publications.

McPherson, M. - Nunes, M. (2006): Organisational Issues for E-Learning: Critical Success Factors as Identified by HE Practitioners, International Journal of Educational Management 20(7): 542-558.

Mercer, J. (2007): The Challenges of Insider Research in Educational Institutions: Wielding a DoubleEdged Sword and Resolving Delicate Dilemmas. Oxford Review of Education 33(1): 1-17.

Messikomer, E. (1987): Marketing Changes the Corporate Culture - A Company Study. The Journal of Business \& Industrial Marketing 2(4): 53-58.

Narver, J. - Slater, S. (1990): The Effect of a Market Orientation on Business Profitability. Journal of Marketing 54(4): 20-35.

Narver, J. - Slater, S. - Tietje, B. (1998): Creating a Market Orientation. Journal of Market-Focused Management 2(3): 241-255.

Nunan, T. (1999): Exploring the Concept of Flexibility. In: Jakupec, V. - Garrick, J. (eds): Flexible Learning, Human Resource and Organisational Development: Putting Theory to Work. Abingdon: Routledge, pp. 63-82.

OECD (2017): Supporting Entrepreneurship and Innovation in Higher Education in Hungary. Paris: OECD Publishing.

Ottesen, G. - Grønhaug, K. (2002): Managers' Understanding of Theoretical Concepts: The Case of Market Orientation. European Journal of Marketing 36(11/12): 1209-1224. 
Ottesen, G. - Grønhaug, K. (2004): Barriers to Practical Use of Academic Marketing Knowledge. Marketing Intelligence \& Planning 22(5): 520-530.

Papadimitriou, A. - Kargas, A. (2012): The Relationship between Organizational Culture and Market Orientation in the Greek Telecommunication Companies. Netnomics 13(1): 1-23.

Parker, A. - Tritter, J. (2006): Focus Group Method and Methodology: Current Practice and Recent Debate. International Journal of Research \& Method in Education 29(1): 23-37.

Perryer, C. - Egan, V. (2015): Business School Accreditation in Developing Countries: A case in Kazakhstan. Journal of Eastern European and Central Asian Research 2(2): 11.

Quinn, R. E. - Rohrbaugh, J. (1983): A Spatial Model of Effectiveness Criteria: Towards a Competing Values Approach to Organizational Analysis. Management Science 29: 363-377.

Raaij, E. - Stoelhorst, J. (2008): The Implementation of a Market Orientation. European Journal of Marketing 42(11/12): 1265-1293.

Ravishankar, M. N. - Pan, S. L. - Leidner, D. E. (2011): Examining the Strategic Alignment and Implementation Success of a KMS: A Subculture-Based Multilevel Analysis. Information Systems Research 22(1): 39-59.

Saldaña, J. (2013): The Coding Manual for Qualitative Researchers. London: Sage.

Sarkar, S. - Vance, A. - Ramesh, B. - Demestihas, M. - Wu, D. (2020): The Influence of Professional Subculture on Information Security Policy Violations: A Field Study in a Healthcare Context. Information Systems Research 31(4): 1240-1259.

Schein, E. (1995): The Role of the Founder in Creating Organizational Culture. Family Business Review 8(3): 221-238.

Schein, E. (2004): Organizational Culture and Leadership. Jossey-Bass.

Silverman, D. (2015): Interpreting Qualitative Data. London, UK: Sage.

$\mathrm{Su}$, C. - Parham, L. (2002): Generating a Valid Questionnaire Translation for Cross-Cultural Use. American Journal of Occupational Therapy 56(5): 581-585.

Trowler, P. (2012): Wicked Issues in Situating Theory in Close-Up Research. Higher Education Research \& Development 31(3): 273-284.

Tummons, J. (2020): Higher Education, Theory, and Modes of Existence: Thinking about Universities with Latour. Higher Education Research \& Development, https://doi.org/10.1080/07294360.2020.1804337.

Vaikunthavasan, S. - Jebarajakirthy, C. - Shankar, A. (2019): How to Make Higher Education Institutions Innovative: An Application of Market Orientation Practices. Journal of Non-profit \& Public Sector Marketing 31(3): 274-302.

Vasilache, S. - Temesi, J. - Dima, A. (2012): Higher Education Reforms in Eastern Europe. A HungarianRomanian case study. Management \& Marketing 7(2): 295-322.

Webster, R.L. - Hammond, K.L. (2018): Is Business School Performance Impacted by Market Orientation toward Students, Employers of Students, and Parents of Students? Journal of Modern Accounting and Auditing 14(2): 49-59.

Zebal, M. - Goodwin, D. (2012): Market Orientation and Performance in Private Universities. Marketing Intelligence \& Planning 30(3): 339-357.

Open Access. This is an open-access article distributed under the terms of the Creative Commons Attribution 4.0 International License (https://creativecommons.org/licenses/by/4.0/), which permits unrestricted use, distribution, and reproduction in any medium, provided the original author and source are credited, a link to the CC License is provided, and changes - if any - are indicated. (SID_1) 